\title{
Anterior Endometrium
}

National Cancer Institute

\section{Source}

National Cancer Institute. Anterior Endometrium. NCI Thesaurus. Code C156431.

The part of the endometrium that is located in the anterior uterine wall. 